\title{
The relationship between the normalized difference vegetation index, rainfall, and potential evapotranspiration in a banana plantation of Venezuela
}

\author{
Barlin Orlando Olivares ${ }^{1}$, Franklin Paredes ${ }^{2}$, Juan Carlos Rey ${ }^{3}$, Deyanira Lobo ${ }^{4}$, Stephanie Galvis-Causil ${ }^{5}$ \\ ${ }^{1}$ Universidad de Córdoba, Spain \\ ${ }^{2}$ Universidad Nacional Experimental de los Llanos Ezequiel Zamora, Venezuela \\ ${ }^{3}$ Universidad Central de Venezuela, Instituto Nacional de Investigaciones Agrícolas \\ ${ }^{4}$ Universidad Central de Venezuela \\ ${ }^{5}$ Universidad Gran Colombia, Colombia
}

\begin{tabular}{|c|c|}
\hline ARTICLE INFO & ABSTRACT \\
\hline Keywords: & The water supply for rainfed crops such as bananas in the Aragua State of Venezuela is often \\
\hline Agrometeorology & uncertain, particularly towards the beginning of the rainy season (April-May). Where climatic \\
\hline Biomass & nditions are seasonal, the temporal evolution of the NDVI (Normalized Difference \\
\hline Musaceae & Vegetation Index) closely accompanies the interannual variation of vegetation growth in \\
\hline NDVI & sponse to thermal and hydric factors. The study aims to assess the relationship between \\
\hline Time series & $\begin{array}{l}\text { NDVI, rainfall and potential evapotranspiration during the period of January/2016 to } \\
\text { December/2017 in a Venezuelan banana plantation. In this study, the NDVI derived from the }\end{array}$ \\
\hline Article history & GIMMS MODIS Terra product, the daily accumulated precipitation data $(\mathrm{mm})$ and the daily \\
\hline Submitted: 2021-04-13 & mean air temperature $\left({ }^{\circ} \mathrm{C}\right)$ were used as the only way to estimate the potential \\
\hline Accepted: 2021-05-28 & evapotranspiration. The results showed that the GMOD09Q1-based NDVI reflects reasonably \\
\hline Available online: $2021-06-25$ & well the spatiotemporal variation in biomass accumulation. Besides, this provides \\
\hline Published regularly: June 2021 & $\begin{array}{l}\text { information on the water stress conditions in banana plants at the plot level. The influence of } \\
\text { precipitation and potential evapotranspiration on the NDVI was more evident when a lag of }\end{array}$ \\
\hline * Corresponding Author & 1 month was considered in terms of the Spearman $r$, implying that there is a delay in the \\
\hline Email address: & banana phonological response to rainfall changes and dryness conditions. However, due to \\
\hline & $\begin{array}{l}\text { its low spatial resolution (i.e. } 250 \mathrm{~m} \text { ), it is not adequate for the identification of banana wilt } \\
\text { disease. Therefore, future studies are needed to assess other satellite-derived spectral indices } \\
\text { for monitoring the health of banana plants over different sites in Venezuela. }\end{array}$ \\
\hline
\end{tabular}

How to Cite: Olivares, B. O., Paredes, F., Rey, J. C., Lobo, D., Galvis-Causil, S. (2021). The relationship between the normalized difference vegetation index, rainfall, and potential evapotranspiration in a banana plantation of Venezuela [Research]. Sains Tanah Journal of Soil Science and Agroclimatology, 18(1): 58-64. https://dx.doi.org/10.20961/stjssa.v18i1.50379

\section{Introduction}

The banana (Musa spp.) is a crop extremely important with a marked geographic dispersion in Latin America and the Caribbean, placing itself as a basic element in food security (Olivares et al., 2020). Its production in Venezuela is largely done traditionally and represents a key source of income for the small producers. The area under banana production in the country exceeds 40,000 hectares (Olivares et al., 2021). During the last 20 years, banana production has undergone slight changes, reaching 424,649 tons with a yield of around 13.91 tons $\mathrm{ha}^{-1}$ in 2017 . This yield is relatively low compared with those obtained for other tropical countries (e.g. Brazil: 14.27 tons $\mathrm{ha}^{-1}$ ), as a consequence of the shortage of agricultural inputs (fertilizers and agrochemicals), problems of access to foreign currency to meet domestic demand, and the inadequate management of agricultural policies, the impact of drought, likewise pests and diseases (MartínezSolórzano et al., 2020).

Due to the large spatial extension of banana plantations in the world, there is a huge need to develop low-cost tools to monitor biomass production on the soils. In this context, remote sensing technologies have captured the interest of the global banana industry. Over the last two decades, a plethora of satellite-based spectral vegetation indices (VIs) have been developed to monitor the health and condition of 


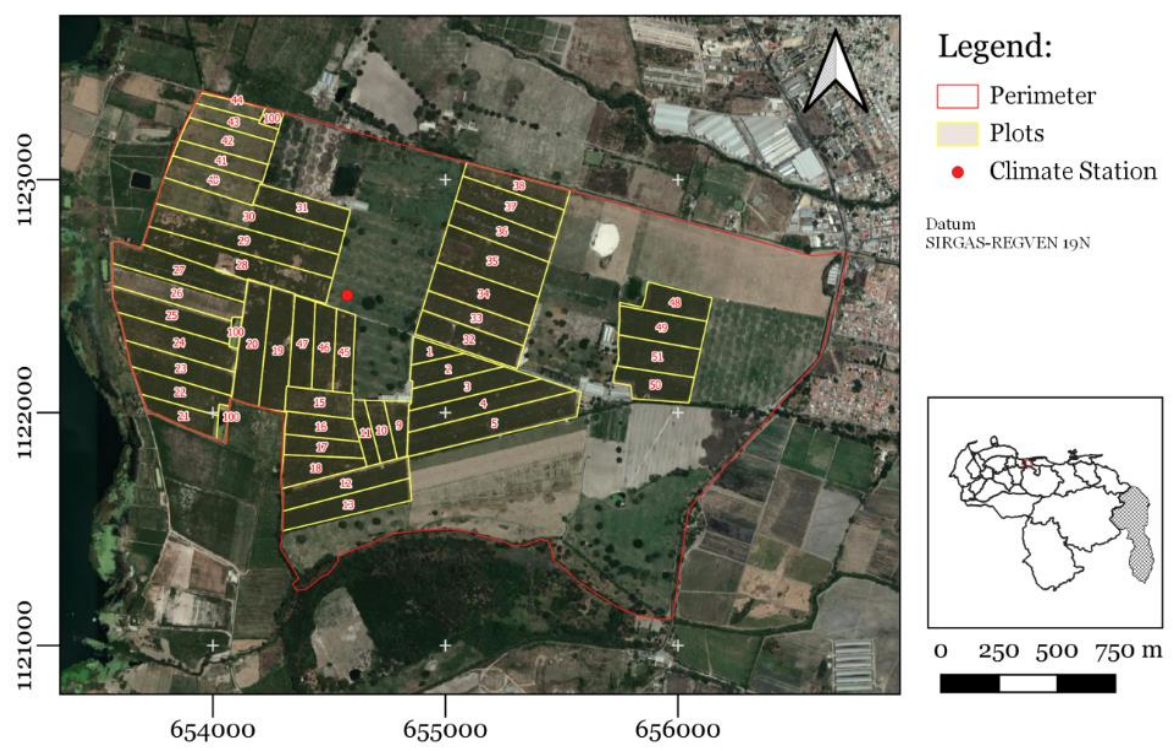

Figure 1. The geographical location of the study area with banana plots

the crops or vegetation. An example of this is the Normalized Difference Vegetation Index (NDVI), which has demonstrated its usefulness as a bioindicator of aerial biomass production in vegetation (Jedermann et al., 2014; Machovina et al., 2016; Ye et al., 2020), also allows estimating the atmospheric demand of water in terms of the potential evapotranspiration (PE) (Alam et al., 2018; Zhou et al., 2021). Despite these important features, the Venezuelan banana sector does not usually contemplate the operational use of VIs in its management plans.

In Venezuela, the Aragua State holds the main bananaproducing areas, which are mostly based on rainfed systems. Therefore, they are highly dependent on rainfall. In this sense, and motivated by the gaps in our understanding of the relationships among the NDVI, rainfall, and PE within these plantations, the study aims to assess the relationship between these variables during the period January/2016 to December/2017 (hereinafter, the study period) in a Venezuelan banana plantation.

\section{Material and Methods}

\subsection{Description of the study site}

The study was carried out in a banana plantation located in the Aragua State, whose planted area is 205 ha with banana Cavendish cv Pineo Gigante (67.58 $\mathrm{W}, 10.14^{\circ} \mathrm{N}$; Figure 1). These plants have: i) a leaf number from 16 to 18 ; ii) height values ranging from 3.5 to $4.5 \mathrm{~m}$; and iii) a growth period from 9 to 10 months in this site. This region is characterized by a Tropical Savanna climate (Aw). The annual mean rainfall is $980 \mathrm{~mm}$ (Olivares et al., 2020) and shows a marked seasonal pattern with a wet season from May to October. The mean annual temperature is $26.2^{\circ} \mathrm{C}$, whereas the mean annual relative humidity is $70.0 \%$ (Olivares, 2018). The terrain relief is mostly flat (slope ranging $0-2 \%$ ). The predominant types of soil are Mollisols and Entisols, which are mostly of lacustrine origin, with medium textures, high nutrient availability, moderate to good drainage, soil $\mathrm{pH}$ varying from neutral to alkaline, good fertility and high soil organic matter content (Olivares et al., 2020).

\subsection{Data set}

\subsubsection{Normalized Difference Vegetation Index (NDVI)}

The NDVI is based on the ratio of spectral reflectance bands of red and near-infrared bands derived from optical satellite sensors, such as the Moderate Resolution Imaging Spectroradiometer (MODIS) sensor aboard the Terra and Aqua satellites (Gillespie et al., 2018; Sharifi, 2020). For this study, a set of NDVI images was used to monitor the vegetation greenness as a proxy of the biomass production in those banana plots located in the study area (see Figure 1). Each NDVI image was extracted from the MODIS NDVI product (GMOD09Q1) covering the study period of January/2016 to December/2017 (i.e. 89 NDVI images). The GMOD09Q1 product was developed by the Global Inventory Modeling and Mapping Studies (GIMMS) in collaboration with the National Aeronautics and Space Administration (NASA) and the US Department of Agriculture's (USDA) (available at https://glam1.gsfc.nasa.gov) using a correction algorithm based on hierarchical rules for molecular scattering, ozone absorption, aerosols, among other quality standards (Fensholt \& Proud, 2012). The rationale behind the choice of this dataset is related to the fact that the GMOD09Q1-based NDVI dataset has been used for green biomass assessment in a wide variety of banana crops (Johansen et al., 2014; Machovina et al., 2016; Oliveira et al., 2019) and its adequate spatial and temporal resolution (250 $\mathrm{m}$ and 8-day). Further details of the GMOD09Q1-based NDVI dataset can be found in Heck et al. (2019).

\subsubsection{Ground-based observations}

The daily accumulated rainfall ( $P$ in $\mathrm{mm}$ ) and the daily average air temperature ( $T$ in Celsius degrees) during the study period were used. $P$ and $T$ were extracted from a conventional climate station located near the banana plots shown in Figure 1 . The $P$ and $T$ time-series present no missing data and their consistencies were evaluated in terms of data quality and homogeneity as explained in (Blesić et al., 2019). The potential evapotranspiration (PE) (in mm month ${ }^{-1}$ ) was estimated using Thornthwaite's equation (Rahimi et al., 2019), where T is used as a unique input. 
Table 1. Statistical metrics for the NDVI at the plot level during the study period

\begin{tabular}{|c|c|c|c|c|c|c|}
\hline $\begin{array}{c}\text { Plot } \\
{[\#]}\end{array}$ & $\begin{array}{c}\text { Minimum } \\
{[-]}\end{array}$ & $\begin{array}{c}\text { Maximum } \\
{[-]}\end{array}$ & $\begin{array}{c}\text { Mean } \\
{[-]}\end{array}$ & $\begin{array}{c}\text { SD* } \\
{[-]}\end{array}$ & $\begin{array}{c}\mathrm{CV}^{* *} \\
{[\%]}\end{array}$ & $\begin{array}{c}\text { IBW } \\
\text { [\%] }\end{array}$ \\
\hline 1 & 0.576 & 0.868 & 0.750 & 0.072 & 9.627 & 0.064 \\
\hline 2 & 0.564 & 0.920 & 0.756 & 0.074 & 9.749 & 0.080 \\
\hline 9 & 0.656 & 0.900 & 0.774 & 0.057 & 7.339 & 0.149 \\
\hline 11 & 0.680 & 0.904 & 0.800 & 0.055 & 6.825 & 0.248 \\
\hline 12 & 0.524 & 0.924 & 0.786 & 0.088 & 11.170 & 0.066 \\
\hline 18 & 0.508 & 0.920 & 0.778 & 0.084 & 10.784 & 0.115 \\
\hline 19 & 0.536 & 0.876 & 0.796 & 0.070 & 8.781 & 0.101 \\
\hline 21 & 0.564 & 0.880 & 0.754 & 0.079 & 10.517 & 0.241 \\
\hline 23 & 0.640 & 0.912 & 0.792 & 0.058 & 7.374 & 0.168 \\
\hline 25 & 0.436 & 0.888 & 0.726 & 0.092 & 12.631 & 0.147 \\
\hline 27 & 0.560 & 0.900 & 0.727 & 0.084 & 11.513 & ND \\
\hline 28 & 0.636 & 0.900 & 0.759 & 0.069 & 9.144 & 0.234 \\
\hline 30 & 0.436 & 0.880 & 0.721 & 0.108 & 14.979 & 0.150 \\
\hline 31 & 0.532 & 0.856 & 0.721 & 0.075 & 10.416 & 0.342 \\
\hline 33 & 0.528 & 0.912 & 0.725 & 0.094 & 12.966 & 0.225 \\
\hline 36 & 0.576 & 0.896 & 0.743 & 0.081 & 10.902 & 0.458 \\
\hline 38 & 0.484 & 0.840 & 0.715 & 0.095 & 13.217 & 0.311 \\
\hline 43 & 0.296 & 0.880 & 0.678 & 0.132 & 19.469 & ND \\
\hline 45 & 0.596 & 0.868 & 0.773 & 0.059 & 7.684 & 0.320 \\
\hline 48 & 0.464 & 0.836 & 0.683 & 0.093 & 13.572 & ND \\
\hline 49 & 0.396 & 0.836 & 0.684 & 0.096 & 14.050 & ND \\
\hline 50 & 0.472 & 0.828 & 0.679 & 0.089 & 13.093 & ND \\
\hline
\end{tabular}

Remarks: ${ }^{*}$ standard deviation; ${ }^{* *}$ coefficient of variation; ND: no data; IBW = Mean incidence of banana wilt (2016-2017)

\subsection{Methodology}

To ensure a fair comparison of the NDVI from the GMOD09Q1 product with ground-based climate data were selected 22 banana plots whose surface average area was $4.18 \pm 1.3$ ha (i.e. $1,2,9,11,12,18,19,21,23,25,27,28,30$, $31,33,36,38,43,45,48,49$, and 50 in Figure 1), where there was a clear overlap between the banana plot and NDVI pixels. Thus, the values of NDVI were extracted from each selected banana plot. Then, the 8-day NDVI time series were aggregated considering the maximum values of NDVI on a monthly time scale to minimize the effect of cloud contamination, as in Vásquez and Paredes-Trejo (2020). To guarantee temporal coherence, the $\mathrm{P}$ and $\mathrm{PE}$ time series were aggregated on a monthly scale time.

In order to explore the relationships among the NDVI, P, and $\mathrm{PE}$ on a monthly scale time, the Spearman rank correlation coefficient (Akoglu (2018); hereinafter, Spearman r) between the paired values of NDVI against $P$ and $P E$ using a lag time of 0,1 , and 2 months during their common periods was applied. For example, when $\mathrm{P}[\mathrm{t}-\mathrm{k}$ ] versus NDVI [t] where $k=1$, the values of NDVI at a time moment $t$ are compared with the values of $\mathrm{P}$ observed at month $\mathrm{t}-1$. The reason behind this approach is that there is a delay in the vegetation response to the rainfall, as demonstrated in previous studies (Vásquez \& Paredes-Trejo, 2020). The Spearman rank correlation coefficient is adopted due to the predominance of a non-Gaussian distribution in these time series (not shown here). A moderate incidence of the disease called banana wilt (BW) was observed during the study period. BW, caused by a fungus-bacteria complex, is a physiological and metabolic disorder; whose origin is due to the influence of biotic and abiotic factors, such as physical and chemical conditions and potentially pathogenic soil microorganisms. This disease is mainly characterized by the wilting and yellowing of the older leaves (Rey-Brina et al., 2020). For this reason, the effect of its incidence (as the percentage of infected plants at the plot level; hereinafter, incidence of banana wilt (IBW) was considered as an auxiliary variable.

\section{Results}

\subsection{The temporal variability of NDVI}

Figure 2 a shows the variation of the maximum values of NDVI monthly for the banana plots during the study period. These values ranged from 0.296 to 0.924 with a mean equal to 0.741 . Furthermore, they tended to be greater than 0.80 from August to December but tended to be lower than 0.70 from February to April. On the other hand, the maximum NDVI exhibited slightly higher values in 2017 (NDVI mean: 0.752) than that in 2016 (NDVI mean: 0.728), which was related to biomass accumulation in banana plants, as can be seen in Figure $2 \mathrm{~b}$. For the sake of clarity, Figure 3 shows the heatmap of the monthly evolution of the maximum NDVI during the study period for the 22 plots of bananas evaluated. The fact that these characteristics have been observed in the study area, implies the presence of a moderate seasonal and interannual variability in the NDVI.

To explore the variability of NDVI at the plot level, Table 1 summarizes a few statistical metrics during the study period. A low NDVI variability in terms of the coefficient of variation (CV) was observed, which is consistent with the weak seasonal variability shown in Figure 2a. Another interesting feature revealed by NDVI values (Table 1 ) is that its variability does not seem to be related to IBW (Pearson $r$ : 0.014 with $p$ $>0.05)$. 

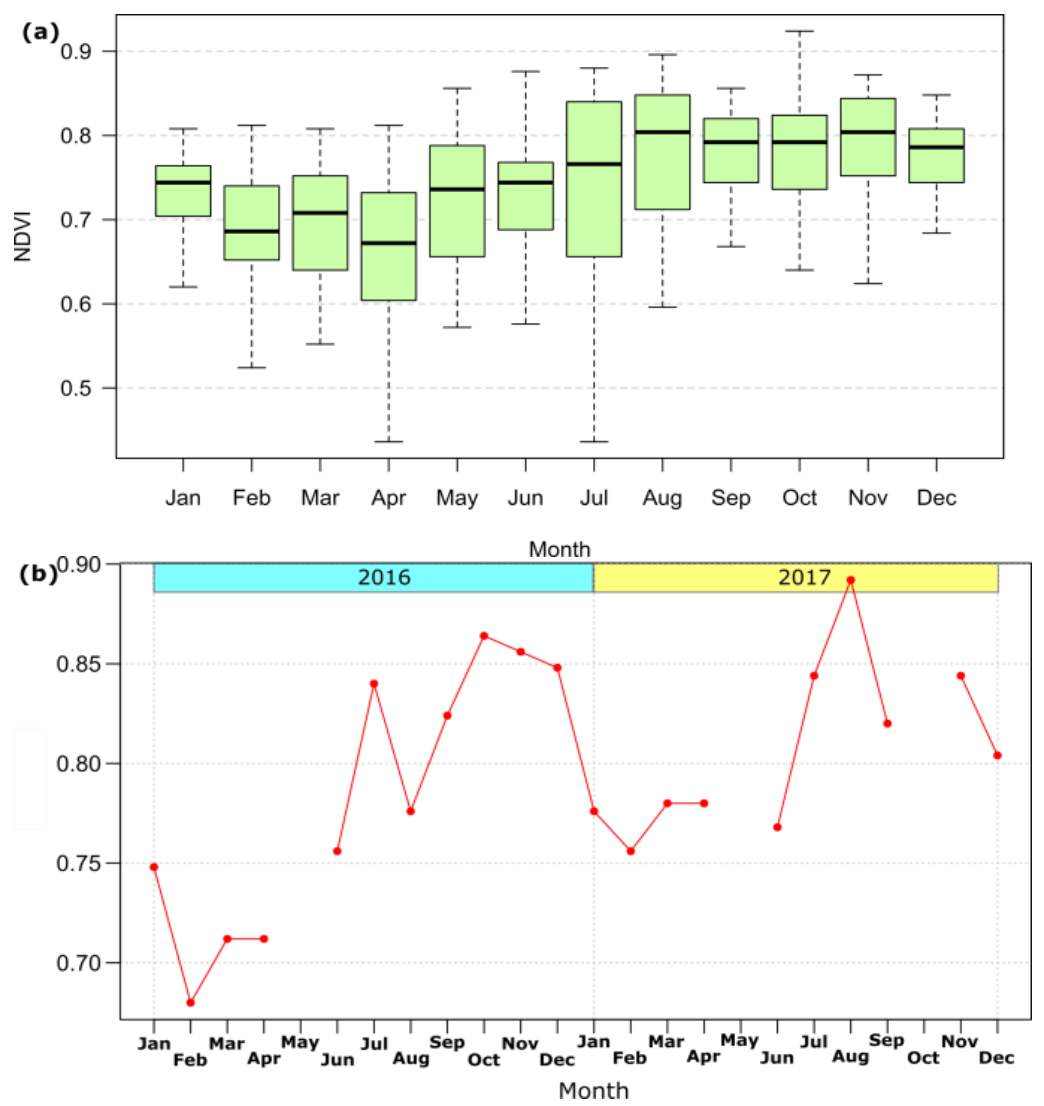

Figure 2. For the study period: (a) boxplots of the maximum values of NDVI for all banana plots. For clarity the outliers were omitted; (b) the maximum values of NDVI for the 22-banana plots shown in Figure 1.

Therefore, caution should be taken when interpreting this result because of the low incidence of banana wilt at the plot level (IBW mean: 0.201). Intuitively, one can infer that the spectral contribution from banana wilt to total variability in NDVI is significantly low compared to that of banana green biomass.

\subsection{The temporal coupling between NDVI, $P$ and $P E$}

This section explores the coupling of NDVI-P and NDVI-PE during the study period in terms of the Spearman $r$. Regardless of the lag time used in the calculation of the Spearman $r$, a predominance of positive values for NDVI-P and negative values for NDVI-PE were observed (Table 2). That is, the occurrence of rain events tended to coincide with higher values of NDVI, while the prevalence of dry conditions reflected by higher $P E$ values tended to be concomitant with lower values of NDVI, revealing the important role of $P$ and $P E$ on the banana phenology. Furthermore, the influence of $P$ and PE on the NDVI was more evident when a lag of 1 month was considered in terms of the Spearman $r$, implying that there is a delay in the banana phonological response to rainfall changes and dryness conditions.

\section{Discussion}

In short, the GMOD09Q1-based NDVI captures reasonably well the temporal and spatial variation in biomass accumulation (Figure 2b). As expected, the values of NDVI showed a seasonal behavior which in turn is largely modulated by the rain events (Table 2), which would be related to the soil moisture availability. These findings agree with previous studies (Johansen et al., 2014; Machovina et al.,
2016). However, the NDVI showed low sensitivity to banana wilt disease in terms of variation of NDVI. One would imagine that NDVI from infected banana plots will show a low NDVI signal at the leaf level, but this characteristic was not observed (see Table 1). The reason for this behavior can be partially attributed to the low spatial resolution from the GMOD09Q1-based NDVI (i.e. $250 \mathrm{~m}$ ), as recent studies have shown (Bouwmeester et al., 2016; Clark \& McKechnie, 2020; Ye et al., 2020). Another factor that could explain the low sensitivity of the NDVI is the fact that the infected banana plants are quickly cut down due to that it is the best way to avoid the dissemination of this disease (Ye et al., 2020), implying a low chance of detection through the maximum monthly NDVI. The above-mentioned findings indicate that this approach should be integrated to in situ additional measurements or complemented with other high-resolution spectral indices for disease monitoring such as the banana wilt.

The results of this study indicated also that the GMOD09Q1-based NDVI provides a moderately accurate picture of the impacts of rainfall and environmental dryness variability on banana plots (Table 2). This is attributed to the fact that as the drought (wet) conditions progress, the leaf chlorophyll content decreases (increases) significantly (Bouwmeester et al., 2016), which, in turn, leads to lower (higher) NDVI over the entire banana plantation. Despite its limitations in terms of early banana wilt detection, the GMOD09Q1-based NDVI has potential as a low-cost operational tool for vegetation stress monitoring triggered by climate conditions across extensive banana plantations in Venezuela, and in this way make a better irrigation scheduling. 
Table 2. Spearman rank correlation coefficients for the NDVI against the $P, P E$, and IBW with lag $=0,1$ and 2 months during the study period

\begin{tabular}{|c|c|c|c|c|c|c|}
\hline \multirow{2}{*}{$\begin{array}{c}\text { Lag [month] } \\
\text { Plot }\end{array}$} & \multicolumn{2}{|c|}{0} & \multicolumn{2}{|c|}{1} & \multicolumn{2}{|c|}{2} \\
\hline & NP1 & NP2 & NP1 & NP2 & NP1 & NP2 \\
\hline [\#] & {$[-]$} & {$[-]$} & {$[-]$} & {$[-]$} & {$[-]$} & {$[-]$} \\
\hline 1 & 0.344 & -0.276 & 0.423 & -0.559 & 0.461 & -0.244 \\
\hline 2 & 0.307 & -0.349 & 0.384 & -0.749 & 0.645 & -0.299 \\
\hline 9 & 0.234 & -0.504 & 0.447 & -0.517 & 0.334 & -0.323 \\
\hline 11 & 0.412 & -0.631 & 0.686 & -0.521 & 0.333 & -0.319 \\
\hline 12 & 0.258 & -0.514 & 0.661 & -0.434 & 0.535 & -0.329 \\
\hline 18 & 0.038 & -0.127 & 0.332 & -0.224 & 0.375 & -0.330 \\
\hline 19 & 0.474 & -0.538 & 0.647 & -0.623 & 0.370 & -0.098 \\
\hline 21 & 0.213 & -0.34 & 0.461 & -0.241 & -0.266 & -0.141 \\
\hline 23 & 0.269 & -0.589 & 0.497 & -0.329 & 0.089 & -0.242 \\
\hline 25 & 0.082 & -0.233 & 0.208 & -0.489 & 0.152 & -0.097 \\
\hline 27 & 0.186 & -0.483 & 0.310 & -0.475 & 0.343 & -0.216 \\
\hline 28 & 0.281 & -0.407 & 0.286 & -0.433 & 0.278 & -0.234 \\
\hline 30 & 0.211 & -0.187 & 0.165 & -0.295 & 0.326 & -0.057 \\
\hline 31 & 0.066 & -0.092 & 0.118 & -0.313 & 0.031 & 0.152 \\
\hline 33 & 0.453 & -0.434 & 0.515 & -0.382 & 0.140 & -0.002 \\
\hline 36 & 0.353 & -0.329 & 0.264 & -0.367 & 0.195 & -0.027 \\
\hline 38 & 0.314 & -0.495 & 0.453 & -0.276 & 0.236 & -0.423 \\
\hline 43 & 0.296 & -0.284 & 0.323 & -0.293 & 0.259 & -0.060 \\
\hline 45 & 0.308 & -0.214 & 0.227 & -0.393 & 0.214 & -0.222 \\
\hline 48 & -0.06 & -0.219 & 0.253 & -0.392 & 0.317 & -0.493 \\
\hline 49 & 0.331 & -0.484 & 0.279 & -0.263 & 0.239 & -0.136 \\
\hline 50 & 0.207 & -0.276 & 0.177 & -0.307 & 0.022 & -0.032 \\
\hline
\end{tabular}

Remarks: NP1 is NDVI vs rainfall (P); NP2 is NDVI vs the potential evapotranspiration (PE)

The results of the NDVI calculation in our studies vary from 0.296 to 0.924 . The zero values in May correspond to missing data during 2016 (see Figure 3). In general, crops or plants will always have positive values between 0.2 and 1 in the tropical conditions of Venezuela (Olivares \& López-Beltrán, 2019). The healthy and dense banana canopy is located above 0.6 according to Johansen et al. (2014) and the scattered vegetation have NDVI values between 0.2 to 0.5 in some banana plots $(48,49,50)$ especially in the dry season in the area (January-April). In our case, the NDVI was a simple indicator of photosynthetically active biomass or, in simple terms, an estimate of the health of the vegetation.

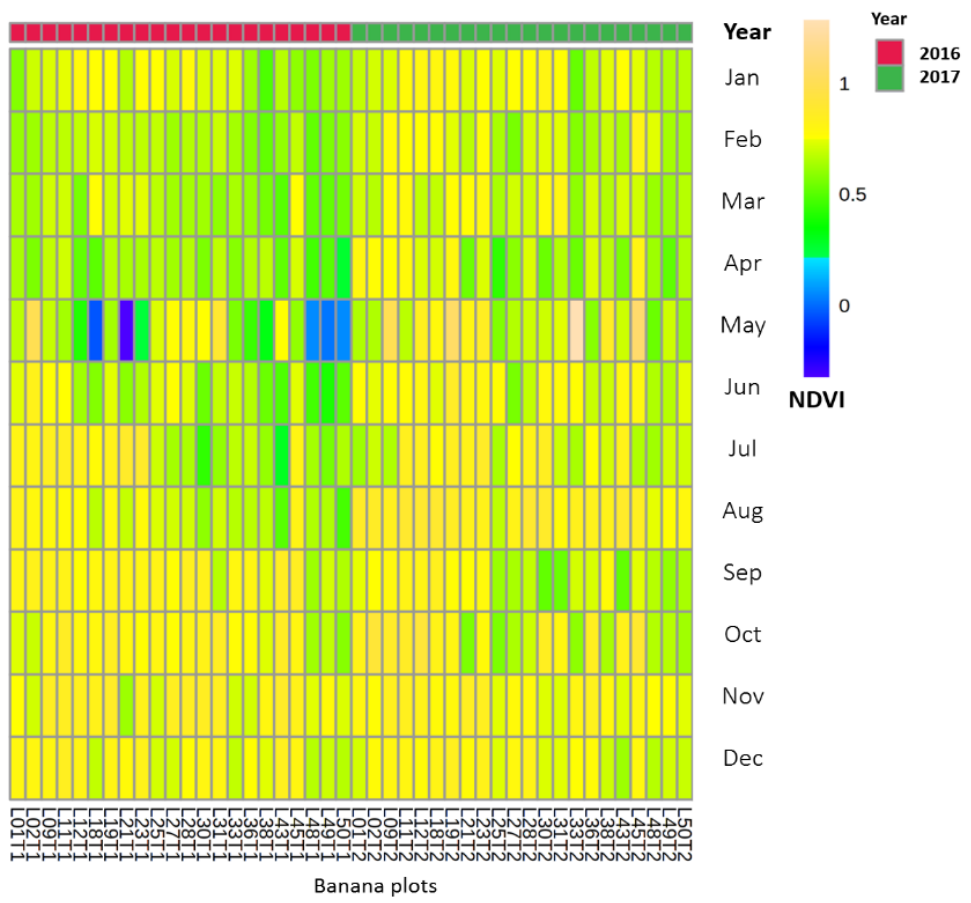

Figure 3. Heatmap of the evolution of the monthly NDVI during the study period for the 22 lots of bananas evaluated. 
The NDVI allowed to differentiate the vegetation from other types of ground cover in the site of interest and to determine its general state. It also allowed to define and visualize areas with vegetation on the map, as well as to detect abnormal changes in the growth process of bananas. To estimate the beginning and end of the annual growth period, (Berger et al., 2019) and (Teixeira et al., 2021) resorted to a simplified hydrological balance model, through which they obtained significant correlations between the humidity index and the NDVI, with a delay in the NDVI signal of 5 weeks during the initial annual growth stage and 6 weeks during the decline stage.

According to Verrelst et al. (2015), the use of multispectral images, favor the effective localization of areas that present stress levels in the crop, before it is visibly manifested, which benefits a selective intervention to specific areas, generating more efficient management. On the other hand, the study by Dannenberg et al. (2020), establishes that the areas that manifest stress in bananas are appreciable although the processing was carried out from Landsat images that have a pixel size of $30 \times 30 \mathrm{~m}$, at a level of precision, better results would be achieved if the processing was carried out with images of drones that have a higher resolution.

Because of its relationship with different agroclimatic elements shown here, Jiang et al. (2017) establishes that the NDVI could be used as an indicator of the beginning of the rain cycle, thus taking advantage of the advantage of having information with complete spatial coverage, as opposed to the strictly local nature of meteorological observation. Before establishing an objective procedure that serves this purpose, it is necessary to investigate, in the state of Aragua, the characteristics of the relationship between different climatic indicators and the NDVI. In this sense, the use of indicators derived from a hydrological balance procedure, eventually integrated with variables that express the thermal aptitude of the region, can be considered a methodological alternative with greater intrinsic capacity to explain plant growth and biomass production.

\section{Conclusion}

This study used NDVI time series derived from the MODIS NDVI product (GMOD09Q1) to assess the relationships among the NDVI, rainfall, and PE in a Venezuelan banana plantation. The results showed that the GMOD09Q1-based NDVI reflects reasonably well the spatiotemporal variation in biomass accumulation. Besides, this provides information on the water stress conditions in banana plants at the plot level. However, due to its low spatial resolution (i.e. $250 \mathrm{~m}$ ), it is not adequate for the identification of banana wilt disease. Therefore, future studies are needed to assess other satellitederived spectral indices with a higher spatial resolution for monitoring the health of banana plants over different sites in Venezuela. Knowing the relationship between rainfall and the productivity of banana crops in the central region of Venezuela would allow better planning of cultivation work and adaptation strategies to different environmental conditions. Additionally, it is possible to carry out this type of analysis for other banana areas with free satellite information.

\section{Acknowledgments}

The authors recognize the financial support of the Campus of International Excellence for Environment, Biodiversity and Global Change (CeiCambio), Spain for international mobility in Universidad La Gran Colombia, Quindío, Colombia.

\section{Declaration of Competing Interest}

The authors declare no competing financial or personal interests that may appear and influence the work reported in this paper.

\section{References}

Akoglu, H. (2018). User's guide to correlation coefficients. Turkish Journal of Emergency Medicine, 18(3), 91-93. https://doi.org/10.1016/j.tjem.2018.08.001

Alam, M. S., Lamb, D. W., \& Rahman, M. M. (2018). A refined method for rapidly determining the relationship between canopy NDVI and the pasture evapotranspiration coefficient. Computers and Electronics in Agriculture, 147, 12-17. https://doi.org/10.1016/j.compag.2018.02.008

Berger, A., Ettlin, G., Quincke, C., \& Rodríguez-Bocca, P. (2019). Predicting the Normalized Difference Vegetation Index (NDVI) by training a crop growth model with historical data. Computers and Electronics in Agriculture, 161, 305-311. https://doi.org/10.1016/j.compag.2018.04.028

Blesić, S., Zanchettin, D., \& Rubino, A. (2019). Heterogeneity of Scaling of the Observed Global Temperature Data. Journal of Climate, 32(2), 349-367. https://doi.org/10.1175/JCLI-D-17-0823.1

Bouwmeester, H., Heuvelink, G. B. M., \& Stoorvogel, J. J. (2016). Mapping crop diseases using survey data: The case of bacterial wilt in bananas in the East African highlands. European Journal of Agronomy, 74, 173184. https://doi.org/10.1016/j.eja.2015.12.013

Clark, A., \& McKechnie, J. (2020). Detecting Banana Plantations in the Wet Tropics, Australia, Using Aerial Photography and U-Net. Applied Sciences, 10(6), 2017. https://doi.org/10.3390/app10062017

Dannenberg, M., Wang, X., Yan, D., \& Smith, W. (2020). Phenological Characteristics of Global Ecosystems Based on Optical, Fluorescence, and Microwave Remote Sensing. Remote Sensing, 12(4), 671. https://doi.org/10.3390/rs12040671

Fensholt, R., \& Proud, S. R. (2012). Evaluation of Earth Observation based global long term vegetation trends - Comparing GIMMS and MODIS global NDVI time series. Remote Sensing of Environment, 119, 131-147. https://doi.org/10.1016/j.rse.2011.12.015

Gillespie, T. W., Ostermann-Kelm, S., Dong, C., Willis, K. S., Okin, G. S., \& MacDonald, G. M. (2018). Monitoring changes of NDVI in protected areas of southern California. Ecological Indicators, 88, 485-494. https://doi.org/10.1016/j.ecolind.2018.01.031

Heck, E., de Beurs, K. M., Owsley, B. C., \& Henebry, G. M. (2019). Evaluation of the MODIS collections 5 and 6 for change analysis of vegetation and land surface temperature dynamics in North and South America. 
ISPRS Journal of Photogrammetry and Remote Sensing, 156, 121-134. https://doi.org/10.1016/j.isprsjprs.2019.07.011

Jedermann, R., Praeger, U., Geyer, M., \& Lang, W. (2014). Remote quality monitoring in the banana chain. Philosophical Transactions of the Royal Society A: Mathematical, Physical and Engineering Sciences, 372(2017), 20130303. https://doi.org/10.1098/rsta.2013.0303

Jiang, L., Guli·Jiapaer, Bao, A., Guo, H., \& Ndayisaba, F. (2017). Vegetation dynamics and responses to climate change and human activities in Central Asia. Science of The Total Environment, 599-600, 967-980. https://doi.org/10.1016/j.scitotenv.2017.05.012

Johansen, K., Sohlbach, M., Sullivan, B., Stringer, S., Peasley, D., \& Phinn, S. (2014). Mapping Banana Plants from High Spatial Resolution Orthophotos to Facilitate Plant Health Assessment. Remote Sensing, 6(9), 8261-8286. https://doi.org/10.3390/rs6098261

Machovina, B. L., Feeley, K. J., \& Machovina, B. J. (2016). UAV remote sensing of spatial variation in banana production. Crop and Pasture Science, 67(12), 12811287. https://doi.org/10.1071/CP16135

Martínez-Solórzano, G., Rey-Brina, J. C., Rodríguez, D., Jiménez, C., Rodríguez, Y., Rumbos, R., PargasPichardo, R., Manzanilla, E., \& Martínez, E. (2020). Análisis de la situación fitopatológica actual de las musáceas comestibles en Venezuela. Agronomía Tropical, 70, 1-20. https://doi.org/https://doi.org/10.5281/zenodo.4323 272

Olivares, B. O. (2018). Tropical rainfall conditions in rainfed agriculture in Carabobo, Venezuela. LA GRANJA. Revista de Ciencias de la Vida, 27(1), 86-102. https://doi.org/10.17163/Igr.n27.2018.07

Olivares, B. O., Araya-Alman, M., Acevedo-Opazo, C., Rey, J. C., Cañete-Salinas, P., Kurina, F. G., Balzarini, M., Lobo, D., Navas-Cortés, J. A., Landa, B. B., \& Gómez, J. A. (2020). Relationship Between Soil Properties and Banana Productivity in the Two Main Cultivation Areas in Venezuela. Journal of Soil Science and Plant Nutrition, 20(4), 2512-2524. https://doi.org/10.1007/s42729-020-00317-8

Olivares, B. O., \& López-Beltrán, M. A. (2019). Normalized Difference Vegetation Index (NDVI) applied to the agricultural indigenous territory of Kashaama, Venezuela. UNED Research Journal, 11(2). https://doi.org/10.22458/urj.v11i2.2299

Olivares, B. O., Rey, J. C., Lobo, D., Navas-Cortés, J. A., Gómez, J. A., \& Landa, B. B. (2021). Fusarium Wilt of Bananas: A Review of Agro-Environmental Factors in the Venezuelan Production System Affecting Its
Development. Agronomy, 11(5), 986. https://doi.org/10.3390/agronomy11050986

Oliveira, C. W., da Silva, W. N., Campos, P. E. R., Meireles, A. C. M., \& Batista, D. d. S. (2019). Detection of banana crop expansion in cariri cearense by orbital images. Revista Brasileira de Agricultura Irrigada, 13(5), 36763682. https://doi.org/10.7127/rbai.v13n5001130

Rahimi, J., Khalili, A., \& Butterbach-Bahl, K. (2019). Projected changes in modified Thornthwaite climate zones over Southwest Asia using a CMIP5 multi-model ensemble. International Journal of Climatology, 39(12), 45754594. https://doi.org/10.1002/joc.6088

Rey-Brina, J. C., Martínez-Solórzano, G., Ramírez, H., \& Pargas-Pichardo, R. (2020). Relación de las condiciones agroecológicas de un lote de planicie lacustrina con la marchitez del banano Cavendish en Aragua, Venezuela. Agronomía Tropical, 70, 1-12. https://doi.org/10.5281/zenodo.4346251

Sharifi, A. (2020). Remotely sensed vegetation indices for crop nutrition mapping. Journal of the Science of Food and Agriculture, 100(14), 5191-5196. https://doi.org/10.1002/jsfa.10568

Teixeira, A. H. d. C., Leivas, J. F., Pacheco, E. P., Garçon, E. A. M., \& Takemura, C. M. (2021). Biophysical Characterization and Monitoring Large-Scale Water and Vegetation Anomalies by Remote Sensing in the Agricultural Growing Areas of the Brazilian Semi-Arid Region. In Advances in Remote Sensing for Natural Resource Monitoring (pp. 94-109). https://doi.org/10.1002/9781119616016.ch7

Vásquez, Z. E., \& Paredes-Trejo, F. (2020). SINCRONIZADA TEMPORAL ENTRE EL ÍNDICE DE VEGETACIÓN NDVI Y LA PRECIPITACIÓN EN UNA PLANTACIÓN DE Eucalyptus spp. Revista Agrollania de Ciencia y Tecnología, $19, \quad 75 \quad$ - $\quad 79$. http://revistas.unellez.edu.ve/index.php/agrollania/a rticle/view/969

Verrelst, J., Camps-Valls, G., Muñoz-Marí, J., Rivera, J. P., Veroustraete, F., Clevers, J. G. P. W., \& Moreno, J. (2015). Optical remote sensing and the retrieval of terrestrial vegetation bio-geophysical properties - A review. ISPRS Journal of Photogrammetry and Remote Sensing, 108, 273-290. https://doi.org/10.1016/j.isprsjprs.2015.05.005

Ye, H., Huang, W., Huang, S., Cui, B., Dong, Y., Guo, A., Ren, Y., \& Jin, Y. (2020). Recognition of Banana Fusarium Wilt Based on UAV Remote Sensing. Remote Sensing, 12(6), 938. https://doi.org/10.3390/rs12060938

Zhou, R., Wang, H., Duan, K., \& Liu, B. (2021). Diverse responses of vegetation to hydroclimate across temporal scales in a humid subtropical region. Journal of Hydrology: Regional Studies, 33, 100775. https://doi.org/10.1016/j.ejrh.2021.100775 